\title{
The Adequate Number of Histopathology Cross-sections of Temporal Artery Biopsy in Establishing the Diagnosis of Giant Cell Arteritis
}

\author{
Roshanak Ali-Akbar Navahi, MD; Samira Chaibakhsh, PhD; Sayyed Amirpooya Alemzadeh, MD \\ Kaveh Abri Aghdam, MD, PhD
}

Eye Research Center, The Five Senses Institute, Rassoul Akram Hospital, Iran University of Medical Sciences, Tehran, Iran

ORCID:

Roshanak Ali-Akbar Navahi: https://orcid.org/0000-0002-8497-5053

Kaveh Abri Aghdam: https://orcid.org/0000-0001-7568-6455

\section{Abstract}

Purpose: To determine the appropriate number of histopathological cross-sections that are required for a conclusive diagnosis of giant cell arteritis (GCA).

Methods: In this cross-sectional study, the number of sections per slide for paraffin-embedded blocks for 100 randomly selected cases where GCA was suspected and those for negative temporal artery biopsies (TABs) were compared with the number of cross-sections per specimen for eight positive-TABs. All aforementioned examinations were conducted at our center from 2012 to 2016. Then, negative-TABs were retrieved and re-evaluated using light microscopy considering the histopathological findings of GCA.

Results: Ninety-five paraffin blocks were retrieved. The original mean biopsy length was $15.39 \pm$ $7.56 \mathrm{~mm}$. Comparison of the mean number of cross-sections per specimen for both the positiveand negative-TABs $(9.25 \pm 3.37$ and $9.53 \pm 2.46)$ showed that $9.87 \pm 2.77$ [95\% confidence intervals $(\mathrm{Cl})$ ] cross-sections per specimen were sufficient for a precise GCA diagnosis. There was no statistically significant difference in the mean biopsy length $(P=0.142)$ among the eight positive-TABs. Similarly, no significant difference was observed in the number of cross-sections per specimen $(P=0.990)$ for positive-TABs compared to those for the negative-TABs. After the retrieval of negative-TABs, the mean number of total pre- and post-retrieval cross-sections per specimen was $17.66 \pm 4.43$. Among all retrieved specimens, only one case $(0.01 \%)$ showed the histopathological features of healed arteritis.

Conclusion: Positive-TABs did not reveal more histological cross-sections than the negative ones and increasing the number of cross-sections did not enhance the accuracy of TAB.

Keywords: Giant Cell Arteritis; Histopathology Cross-sections; Temporal Artery Biopsy

J Ophthalmic Vis Res 2021; 16 (1): 77-83

\section{Correspondence to:}

Kaveh Abri Aghdam, MD, PhD. Department of Ophthalmology, Eye Research Center, The Five Senses Institute, Rassoul Akram Hospital, Niayesh Ave., Sattarkhan St., Tehran 14456, Iran.

E-mail: kaveh.abri@gmail.com

Received: 24-07-2019 Accepted: 22-09-2020

\section{Access this article online}

\section{Website:}

https://knepublishing.com/index.php/JOVR

DOI:

10.18502/jovr.v16i1.8253

\section{INTRODUCTION}

Giant cell arteritis (GCA) is characterized by granulomatous vasculitis of large and mediumsized vessels, and its worldwide annual

This is an open access journal, and articles are distributed under the terms of the Creative Commons Attribution-NonCommercial-ShareAlike 4.0 License, which allows others to remix, tweak, and build upon the work non-commercially, as long as appropriate credit is given and the new creations are licensed under the identical terms.

How to cite this article: Navahi RAA, Chaibakhsh S, Alemzadeh SA, Abri Aghdam K. The Adequate Number of Histopathology Cross-sections of Temporal Artery Biopsy in Establishing the Diagnosis of Giant Cell Arteritis. J Ophthalmic Vis Res 2021;16:77-83. 
incidence rate ranges from 1.28 to 29.1 per 100,000 among individuals aged over 50 years. ${ }^{[1-3]}$ Approximately $15-20 \%$ of GCA patients may develop permanent loss of vision. ${ }^{[4]}$ As per the guidelines of the American College of Rheumatologists (ACR), diagnosis of GCA is primarily based on the presence of characteristic clinical features and laboratory findings of elevated levels of acute-phase reactants. ${ }^{[5-7]}$ Temporal artery biopsy (TAB) is considered as the gold standard diagnostic test for GCA. ${ }^{[8,9]} A$ positive-TAB test is mainly defined as vasculitis with infiltration of mononuclear cells with or without the presence of multinucleated giant cells, disruption of the internal elastic lamina, and intimal hyperplasia. ${ }^{[10-12]}$ However, sometimes TAB may indicate intermediate findings that make it difficult to distinguish GCA from other pathologies such as healed arteritis or even arteriosclerosis that occurs in elderly patients. ${ }^{[13,14]}$ Thus, TAB has low sensitivity and it may show negative results in 15$40 \%$ of patients. ${ }^{[15-19]}$ Additionally, the number of biopsies, length of the artery sampled, sectioning techniques, and histopathological criteria for diagnosing arteritis, presence of skip lesions, and previous treatment with corticosteroids may contribute to false-negative results. ${ }^{[20,21]}$

This study was performed at a tertiary referral center to determine the appropriate number of cross-sections for a TAB examination that are required for a conclusive GCA diagnosis.

\section{METHODS}

In our center, TAB cross-sections are routinely cut into 2-3 mm-long slices and each of them is embedded transversely in a paraffin block. Next, hematoxylin and eosin-stained serial sections of 5$\mu \mathrm{m}$ thickness are prepared at three-step levels with 25- $\mu \mathrm{m}$ intervals. TAB specimens are considered positive if a narrow lumen, irregular intimal thickening, and fragmentation of the internal elastic lamina with inflammation of the vessel wall (composed of lymphocytes and epithelioid histiocytes with or without multinucleated giant cells) are observed. In borderline cases including those wherein inflammation is limited to the adventitia, additional levels are requested. In this cross-sectional study, the histopathology reports of 205 archived temporal artery biopsies (TABs; performed between 2012 and 2016) were re-evaluated. The length of the biopsy and total number of cross-sections per specimen for eight positive-TAB cases were compared with those for a 100 computer-assisted randomly selected negative-TABs, which were performed during the same period. Then, paraffin-embedded blocks of these original negative-TABs were retrieved and $>90 \%$ of each paraffin block was sectioned. A single ophthalmic pathologist (RAAN) re-evaluated all the newly retrieved sections, considering the previously mentioned histopathological findings that characterize GCA. The methods and main outcomes of the study have been summarized in Figure 1. In addition, the revised ACR-2016 ( $\mathrm{rACR}$ ) scores from the available medical records of patients with positiveand negative-TABs conducted in 2016 were evaluated.

SPSS software version 22.0 (IBM Corp., Armonk, NY) was used for statistical analyses. Results are reported as mean \pm standard deviation. The Mann-Whitney $U$ test was used to analyze quantitative variables. $P$-value $<0.05$ was considered statistically significant.

\section{RESULTS}

Of the total 205 TABs conducted during 20122016, eight reports were positive for GCA. From the remaining 197 negative biopsies, initially a 100 paraffin-embedded blocks were randomly selected for retrieval. Since five paraffin blocks were not suitable for retrieval, finally the results of 95 specimens were evaluated.

The mean age of the patients was $62.75 \pm 12.83$ years and $54 \%$ were female. Two patients had nonsimultaneous bilateral biopsies. The mean biopsy length was $15.39 \pm 7.56 \mathrm{~mm}$.

The number of slides per specimen, crosssections per slide, and the number of slides per $\mathrm{mm}$ of biopsy length before and after retrieval have been summarized in Table 1.

In the eight positive-TAB specimens, the mean artery length was $16.70 \pm 8.48 \mathrm{~mm}$ and the mean number of cross-sections per specimen was 9.25 \pm 3.37 . No statistically significant differences were found in the biopsy length $(P=0.142)$ and the number of cross-sections per specimen $(P=0.990)$ among the eight positive-TABs and when the positive TABs were compared to the pre-retrieval negative-TABs (Table 1). Comparison of the number of cross-sections per specimen for pre-retrieval 


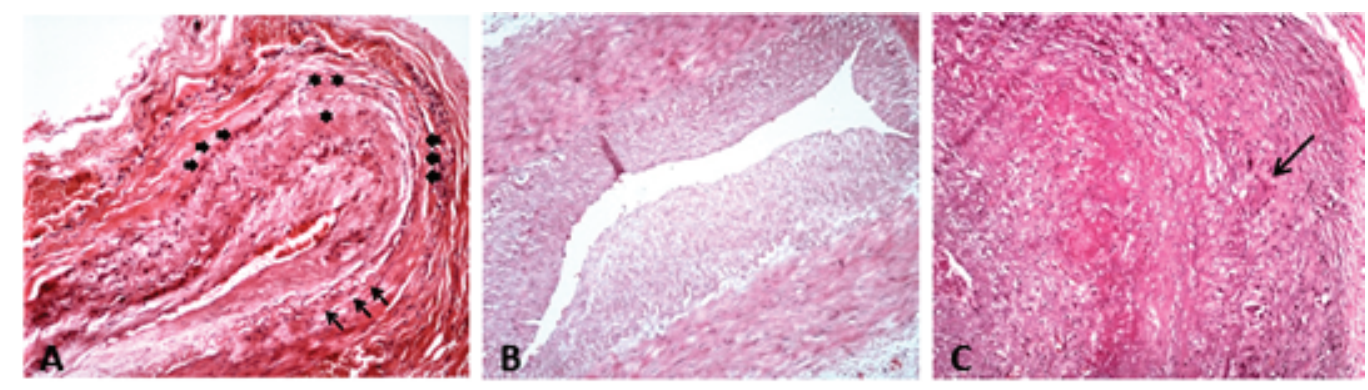

Figure 1. (A) Healed arteritis: note the narrow lumen and minimal intramural lymphocytic infiltration, scarring, and fibrosis (asterisks) in areas with destroyed elastic lamina (short arrows) compared to the areas of intact elastic lamina (long arrows), (H\&E staining $\times 40)$. (B) Normal artery, negative for GCA (H\&E staining $\times 40)$. (C) Active GCA: note the obstruction of the lumen, arterial wall thickening, elastic lamina fragmentation, and intramural inflammation with multinucleated giant cells (arrow), (H\&E staining $\times 100)$. GCA, giant cell arteritis; H\&E, Hematoxylin and Eosin

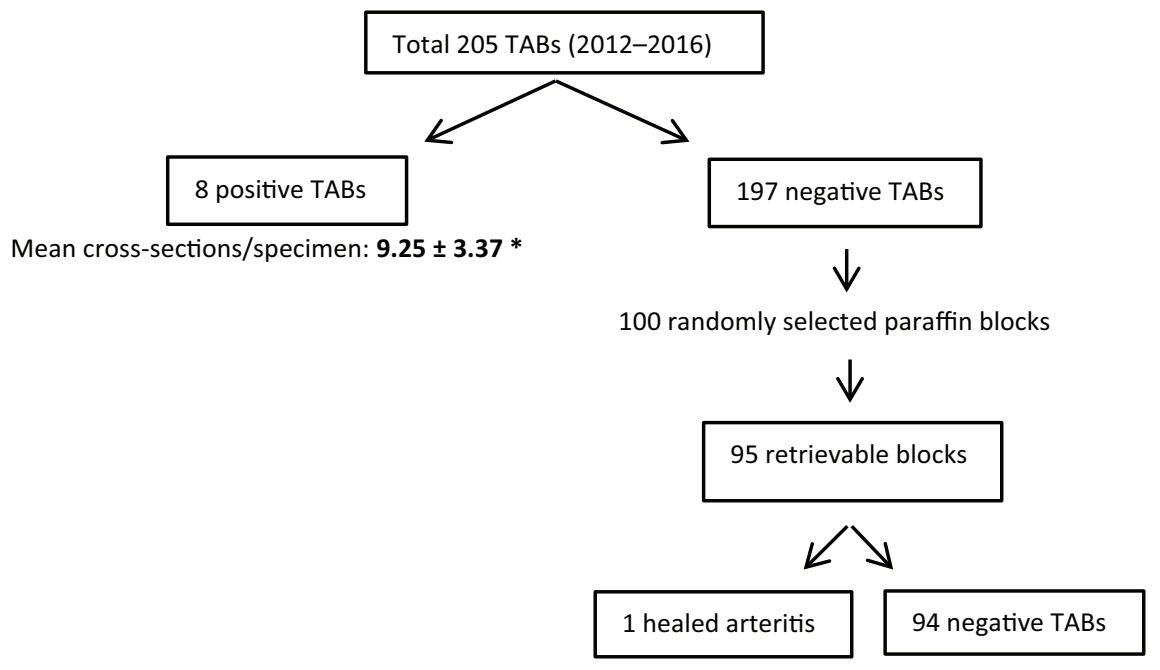

Mean pre-retrieval cross-sections/specimen: $9.53 \pm 2.46 *$

Mean post-retrieval cross-sections/specimen: $8.12 \pm 3.09$

Total pre- and post-retrieval cross-sections/specimen: $17.66 \pm 4.43$

Figure 2. Summary of the methods and main outcomes of the study.

*There was no significant difference in the mean number of cross-sections per specimen between the positive- and original negative-TABs $(P=0.990)$. Based on the comparison of these two items, $9.87 \pm 2.77$ (95\% confidence intervals) cross-sections per specimen were considered sufficient for precise results.

In addition, retrieval of the original negative-TABs at multiple levels did not enhance the accuracy of TAB for diagnosing GCA. GCA, giant cell arteritis; TAB, temporal artery biopsy

negative-TABs $(9.53 \pm 2.46)$ and those for the eight positive-TABs $(9.25 \pm 3.37)$ showed that $9.87 \pm 2.77$ [95\% confidence intervals (Cl): 9.16-10.59] crosssections per specimen were sufficient for precise diagnostic results.

In the clinical evaluation of 95 negativeTABs, we only found 50 cases with complete medical records that met the 2016 rACR criteria, ${ }^{[7]}$ and the mean overall rACR score for these patients was $3.86 \pm 1.12$. In contrast, the mean overall $\mathrm{rACR}$ score for the eight patients with positive TABs in our study was 5.87 .

Histopathological evaluation of retrieved biopsies revealed only one case $(0.01 \%)$ of healed arteritis with mild intramural lymphocytic infiltration, narrowing of the lumen, fragmentation, and destruction of the internal elastic lamina with scarring of the artery wall (Figure 1). This patient had an rACR score of 3 , and had undergone bilateral $\mathrm{TAB}$, with original pathology reports showing negative results for GCA. 
Table 1. Comparison of positive- and negative-TABs (pre- and post-retrieval)

\begin{tabular}{|c|c|c|c|c|}
\hline \multirow[t]{2}{*}{ Parameter } & \multicolumn{2}{|c|}{ Negative-TAB ( $N=95)$} & \multirow{2}{*}{$\begin{array}{c}\text { Positive-TAB }(N=8) \\
\text { (original) }\end{array}$} & \multirow{2}{*}{$\begin{array}{c}P \text {-value (between } \\
\text { positive-TABs and } \\
\text { pre-retrieval } \\
\text { negative-TABs) }\end{array}$} \\
\hline & $\begin{array}{l}\text { Pre-retrieval } \\
\text { (original) }\end{array}$ & Post-retrieval & & \\
\hline Mean biopsy length (mm) & $15.39 \pm 7.56$ & $N / A$ & $16.70 \pm 8.48$ & $P=0.142$ \\
\hline $\begin{array}{l}\text { Mean number of } \\
\text { slides/specimen }\end{array}$ & $3.24 \pm 0.74$ & $2.83 \pm 0.96$ & $3.25 \pm 0.82$ & $\mathrm{~N} / \mathrm{A}$ \\
\hline $\begin{array}{l}\text { Mean number of } \\
\text { cross-sections/slide }\end{array}$ & $2.93 \pm 0.26$ & $2.84 \pm 0.39$ & $2.87 \pm 0.36$ & $N / A$ \\
\hline $\begin{array}{l}\text { Mean number of } \\
\text { cross-sections/specimen }\end{array}$ & $9.53 \pm 2.46$ & $8.12 \pm 3.09$ & $9.25 \pm 3.37$ & $P=0.990^{*}$ \\
\hline $\begin{array}{l}\text { Mean number of } \\
\text { cross-sections } / \mathrm{mm} \text { biopsy } \\
\text { length }\end{array}$ & $0.72 \pm 0.29$ & $\mathrm{~N} / \mathrm{A}$ & $0.55 \pm 0.46$ & $N / A$ \\
\hline $\begin{array}{l}\text { Mean number of total pre- and } \\
\text { post-retrieval } \\
\text { cross-sections/specimen }\end{array}$ & \multicolumn{2}{|c|}{$17.66 \pm 4.43$} & $\mathrm{~N} / \mathrm{A}$ & $\mathrm{N} / \mathrm{A}$ \\
\hline
\end{tabular}

${ }^{*}$ Comparisons of positive-TABs and pre-retrieval negative-TABs

$\mathrm{N} / \mathrm{A}$, not applicable; TAB, temporal artery biopsy

\section{DISCUSSION}

Currently, no specific guidelines have been formulated regarding the adequate number of cross-sections needed for accurate biopsy results of TAB specimens.

Although TAB is considered as the gold standard test for diagnosing GCA, ambiguous findings may lead to inconclusive diagnosis or inaccurate results. ${ }^{[8,9]}$ The extent of sectioning, length of the artery, and presence of skip lesions as well as unilateral or bilateral biopsies are among the factors that may affect TAB results.

Characteristic histopathological findings of active GCA include pan-arteritis that is most pronounced in media, with or without multinucleated giant cells and fragmented internal elastic lamina. In contrast, healed arteritis is characterized by diffuse intimal thickening, intimal and medial fibrosis with variable degree of lymphocytic infiltration, loss of internal elastic lamina, and adventitial scarring which correlates with prior history of GCA symptoms and a higherthan-normal erythrocyte sedimentation rate (ESR). Increased ESR is part of the reparative process and not considered a marker for active arteritis. $^{[22]}$ However, occasionally, it may be difficult to distinguish the aforementioned pathology from changes resulting from aging and atherosclerosis. ${ }^{[23-25]}$

According to the literature, routine evaluation of TABs at multiple levels does not enhance the diagnostic yield and is not cost-effective. ${ }^{[20,26-29]}$ In a study conducted by Taylor et $a{ }^{[29]}$ for determining the threshold specimen length for pathological examination and interpretation, there was no statistically significant difference between the number of total cross-sections per specimen used for positive-TABs (22.3) and those for the negative ones (21.6). In our study, there was no statistically significant difference in the mean biopsy length and mean number of cross-sections per specimen for the eight positive-TABs compared to those of the negative-TABs before retrieval. These results indicate that diagnosis in positiveTAB cases did not require a greater number of cross-sections than those required in negative ones.

Methods for the technical processing of a temporal artery differ across centers. Some centers examine the artery in one longitudinal section and two transverse ones, which may be obtained from either end of the artery if the arterial length is sufficient. ${ }^{[20,29,30]}$ TAB processing at our center is performed using transverse sections 
according to a recommended protocol, ${ }^{[31]}$ with some modifications that have been described in the Methods section.

In this study, we determined that $9.87 \pm 2.77$ cross-sections per specimen were sufficient to achieve precise results at our center. Further, additional retrieval of the negative-TAB specimens did not increase the chances of obtaining positive GCA results. However, additional studies are required to determine the appropriate number of cross-sections for a TAB evaluation.

"Skip lesions," which are foci of discontinuous vasculitis, are found in $8-28 \%$ of GCA-positive biopsies. ${ }^{[23,26,32]}$ Skip lesions are not common in temporal arteritis, and skipped areas are approximately $330 \mu \mathrm{m}$ to $1 \mathrm{~mm}$ in length. ${ }^{[27]}$ Although the idea is controversial, it has been suggested that a length of $5-7 \mathrm{~mm}$ could be the threshold for diagnostic sensitivity of $\operatorname{TAB}^{[27,33]}$ This implies that even short TAB specimens might be sufficient to visualize the histological features of arteritis. ${ }^{[27]}$ Our results indicate that there was only one case of healed arteritis among 95 negative-TAB cases. These results are compatible with those of Chakrabarty et $a l,{ }^{[20]}$ wherein only 1 out of 132 cases showed positive GCA features after performing sections at multiple levels. However, the length of the artery in our positive case was $13 \mathrm{~mm}$. The extent of the agreement between the first and second slide readings using the Kappa coefficient before and after the retrieval of the negative-TAB specimens could not be calculated due to high similarity between the results. However, regardless of statistical significance, there was approximately a 98\% agreement between the two readings since 94 out of 95 negative-TAB specimens were also negative in the second histopathological evaluation.

In general, it is standard to perform a unilateral TAB when GCA is clinically suspected; the contralateral artery biopsy is done if the clinical suspicion is high and the first biopsy is negative. ${ }^{[34]}$ Otherwise, the chance of a positive second biopsy ranges from $5 \%$ to $9 \%,{ }^{[35]}$ and if the clinical suspicion is low, a unilateral biopsy is sufficient to rule out the diagnosis. The single biopsy after retrieval that was positive for healed arteritis was that of a left temporal artery from a 67-year-old female, which was taken seven days after a negative-GCA result from the first biopsy of the right artery. She had been treated with intravenous methylprednisolone for three days followed by oral prednisolone at a dose of $1 \mathrm{mg} / \mathrm{kg}$ before performing TAB.

In general, for cases where GCA is suspected, immediate treatment with high-dose steroids even before a biopsy is recommended. Since the resolution of inflammatory infiltration is usually slow, the chance of detecting active inflammation is not affected by steroid therapy if the biopsy is performed within two weeks. ${ }^{[36]}$ In our case of healed arteritis after retrieval, the specimen was taken seven days after starting steroid therapy. Therefore, the findings could be due to a previous episode of GCA rather than aging-related arterial changes.

The diagnosis of GCA does not always require a positive-TAB, and approximately $15-40 \%$ of patients with GCA are TAB-negative. ${ }^{[15-19]}$ This phenomenon where a high percentage of people who have negative biopsies are diagnosed with GCA has resulted in disagreement among neuroophthalmologists and rheumatologists regarding the criteria for GCA. It has been recommended that TAB should be performed only for patients with rACR scores of 3 and 4 , since there is higher variability in TAB results for other patients. ${ }^{[7]}$ Among the 95 suspected GCA cases with negative TABs, we reviewed the medical records of 50 patients whose mean overall $r A C R$ score was $3.86 \pm 1.12$. These results were similar to those of Abri Aghdam et $a^{[37]}$ (mean score of $3.88 \pm 1.19$ for negative biopsies). In addition, the mean overall rACR score of the eight patients with positive-TABs in our study was 5.87. After retrieval of negative-TABs, we identified only one case of healed arteritis with an rACR score of 3 .

Positron emission tomography ${ }^{[38]}$ and 3 tesla-magnetic resonance imaging ${ }^{[39]}$ are new technologies that are now being regularly used in the diagnosis and monitoring of GCA disease progression. Although, the use of non-invasive color duplex ultrasonography reduces the chances of false-negative TABs due to skip lesions, ${ }^{[40]}$ it is an operator-dependent technique.

It is important to consider that the final diagnosis in TAB-negative patients may indicate a spectrum of conditions mainly including other rheumatologic diseases, presence of non-temporal arteries with GCA, infectious diseases, neoplastic diseases, and neuro-ophthalmic conditions. ${ }^{[7,41]}$

In conclusion, positive-TABs in our study did not require more cross-sections than the negative 
ones. Further, TAB examination at multiple levels did not increase the diagnostic yield of the test. In this study, $9.87 \pm 2.77$ cross-sections per specimen were sufficient for a precise diagnosis of GCA.

\section{Acknowledgements}

The authors would like to thank Dr. Fahimeh Asadi Amoli, Professor of Pathology at the Farabi Eye Hospital for her technical support in providing histology sections.

\section{Financial Support and Sponsorship}

This work was funded by the Eye Research Center of Iran University of Medical Sciences which did not have any role in the design, execution, and presentation of results.

\section{Conflicts of Interest}

There are no conflicts of interest.

\section{REFERENCES}

1. Allsop C, Gallagher P. Temporal artery biopsy in giant cell arteritis: a reappraisal. Am J Surg Pathol 1981;5:317-323.

2. Mambo NC. Temporal (granulomatous) arteritis: a histopathological study of 32 cases. Histopathology 1979;3:209-221.

3. Ramstead CL, Patel AD. Giant cell arteritis in a neuroophthalmology clinic in Saskatoon, 1998-2003. Can J Ophthalmol 2007;42:295-298.

4. Evans JM, Hunder GG. Polymyalgia rheumatica and giant cell arteritis. Rheum Dis Clin North Am 2000;26:493-515.

5. Nesher G, Breuer GS. Giant cell arteritis and polymyalgia rheumatica: 2016 update. Rambam Maimonides Med J 2016;7:e0035.

6. Gajree S, Borooah S, Dhillon N, Goudie C, Smith C, Aspinall $P$ et al. Temporal artery biopsies in south-east Scotland: a five-year review. J R Coll Physicians 2017;47:124-128.

7. Sait MR, Lepore M, Kwasnicki R, Allington J, Balasubramanian R, Somasundaram SK, et al. The 2016 revised ACR criteria for diagnosis of giant cell arteritis - our case series: can this avoid unnecessary temporal artery biopsies? Int J Surg Open 2017;9:19-23.

8. Hall S, Persellin S, Lie JT, O'Brien PC, Kurland LT, Hunder GG., et al. The therapeutic impact of temporal artery biopsy. Lancet 1983;2:1217-1220.

9. Hall S, Hunder GG. Is temporal artery biopsy prudent? Mayo Clin Proc 1984;59:793-796.

10. Nesher $G$. The diagnosis and classification of giant cell arteritis. J Autoimmun 2014;48-49:73-75.

11. Hunder GG, Bloch DA, Michel BA, Stevens MB, Arend WP, Calabrese $\mathrm{LH}$, et al. The American College of Rheumatology 1990 criteria for the classification of giant cell arteritis. Arthritis Rheum 1990;33:1122-1128.
12. Font RL, Prabhakaran VC. Histological parameters helpful in recognising steroid-treated temporal arteritis: an analysis of 35 cases. Br J Ophthalmol 2007;91:204-209.

13. Zhou L, Luneau K, Weyand CM, Biousse V, Newman NJ, Grossniklaus HE. Clinicopathologic correlations in giant cell arteritis: a retrospective study of 107 cases. Ophthalmology 2009;116:1574-1580.

14. Stacy RC, Rizzo JF, Cestari DM. Subtleties in the histopathology of giant cell arteritis. Semin Ophthalmol 2011;26:342-348.

15. Burke A, Virmani R. Temporal artery biopsy of giant cell arteritis. Pathol Case Rev 2001;6:265-273.

16. Egge K, Midtbo A, Westby R. Arteritis temporalis. Acta Ophthalmol 1966;14:49-56.

17. Hauser WA, Ferguson RH, Holley KE, Kurland LT. Temporal arteritis in Rochester Minnesota, 1951 to 1967. Mayo Clin Proc 1971;46:567-602.

18. Roth AM, Milsow L, Keltner JL. The ultimate diagnoses of patients undergoing temporal artery biopsies. Arch Ophthalmol 1984;102:901-903.

19. Salvarani C, Macchioni P, Zizzi F, Mantovani W, Rossi $F$, Castri $C$, et al. Epidemiological and immunogenetic aspects of polymyalgia rheumatica and giant cell arteritis in Northern Italy. Arthritis Rheum 1991;34:351-356.

20. Chakrabarty A, Franks AJ. Temporal artery biopsy: is there any value in examining biopsies at multiple levels? J Clin Pathol 2000;53:131-136.

21. Bhatti MT, Tabandeh $\mathrm{H}$. Giant cell arteritis: diagnosis and management. Curr Opin Ophthalmol 2001;12:393-399.

22. McDonnell PJ, Moore GW, Miller NR, Hutchins GM, Green WR. Temporal arteritis. A clinicopathologic study. Ophthalmology 1986;93:518-530.

23. Lie JT. Temporal artery biopsy diagnosis of giant cell arteritis: lessons from 1109 biopsies. Anat Pathol 1996;1:69-97.

24. Bevan AT, Dunnill MS, Harrison MJ. Clinical and biopsy findings in temporal arteritis. Ann Rheum Dis 1968;2:271277.

25. Ostberg G. Temporal arteritis in a large necropsy series. Ann Rheum Di 1971;30:224-235.

26. Poller DN, Van Wyk Q, Jeffrey MJ. The importance of skip lesions in temporal arteritis. J Clin Pathol 2000;53:137139.

27. Mahr A, Saba M, Kambouchner M, Polivka M, Baudrimont M, Brocheriou I, et al. Temporal artery biopsy for diagnosing giant cell arteritis: the longer, the better? Ann Rheum Dis 2006;65:826-828.

28. Cohen DN, Smith TR. Skip areas in temporal arteritis: myth versus fact. Trans Am Acad Ophthalmol Otolaryngol 1974;78:772-783.

29. Taylor-Gjevre R, Vo M, Shukla D, Resch L. Temporal artery biopsy for giant cell arteritis. J Rheumatol 2005;32:12791282

30. Sharma NS, Gal A, Benger R. Longitudinal sectioning of temporal artery biopsy specimens. Eye 2012;26:15931595.

31. Stone JR, Basso C, Baandrup UT, Bruneval P, Butany J, Gallagher PJ, et al. Recommendations for processing cardiovascular surgical pathology specimens: a consensus statement from the Standards and Definitions 
Committee of the Society for Cardiovascular Pathology and the Association for European Cardiovascular Pathology. Cardiovasc Pathol 2012;21:2-16.

32. Klein RG, Campbell RJ, Hunder GG, Carney JA. Skip lesions in temporal arteritis. Mayo Clin Proc 1976;51:504510.

33. Ypsilantis E, Courtney ED, Chopra N, Karthikesalingam A, Eltayab M, Katsoulas N, et al. Importance of specimen length during temporal artery biopsy. $\mathrm{Br} J$ Surg 2011;98:1556-1560.

34. Miller NR. Giant cell arteritis. J Neuroophthalmol 2000;20:219-220.

35. Hayreh SS, Podhajsky PA, Raman R, Zimmerman B. Giant cell arteritis: validity and reliability of various diagnostic criteria. Am J Ophthalmol 1997;12:285-296.

36. Achkar AA, Lie JT, Hunder GG, O'Fallon WM, Gabriel SE. How does previous corticosteroid treatment affect the biopsy findings in giant cell (temporal) arteritis? Ann Intern Med 1994;120:987-992.
37. Abri Aghdam K, Soltan Sanjari M, Manafi N, Khorramdel S, Alemzadeh SA, Ali Akbar Navahi R. Temporal artery biopsy in diagnosing giant cell arteritis: a ten-year review. J Ophthalmic Vis Res 2020;15:201-209.

38. Blockmans D, Ceuninck L, Vanderschueren S, Knockaert D, Mortelmans L, Bobbaers H. Repetitive 18F-fluorodeoxyglucose positron emission tomography in giant cell arteritis: a prospective study of 35 patients. Arthritis Rheum 2006;55:131-137.

39. Bley TA, Uhl M, Venhoff N, Thoden J, Langer M, Markl M. 3-T MRI reveals cranial and thoracic inflammatory changes in giant cell arteritis. Clin Rheumatol 2007;26:448-450.

40. Ball EL, Walsh SR, Tang TY, Gohil R, Clarke JM. Role of ultrasonography in the diagnosis of temporal arteritis. $\mathrm{Br} \mathrm{J}$ Surg 2010;97:1765-1771.

41. Breuer GS, Nesher R, Nesher G. Negative temporal artery biopsies: eventual diagnoses and features of patients with biopsy-negative giant cell arteritis compared to patients without arteritis. Clin Exp Rheumatol 2008;26:1103-1106. 